NBER WORKING PAPER SERIES

STABILIZATION WITH EXCHANGE RATE MANAGEMENT UNDER UNCERTAINTY

\author{
Allan Drazen
}

Elhanan Helpman

Working Paper No. 2268

\author{
NATIONAL BUREAU OF ECONOMIC RESEARCH \\ 1050 Massachusetts Avenue \\ Cambridge, MA 02138 \\ May 1987
}

For helpful comments we wish to thank seminar participants at the Institute for International Economic Studies, Stockholm, the Hebrew University, and Tel-Aviv University, and participants of the Sapir Center conference on "Economic Effects of the Government Budget". Financial support from the Bank of Israel is gratefully acknowledged. The research reported here is part of the NBER's research program in International Studies. Any opinions expressed are those of the authors and not those of the National Bureau of Economic Research. 
NBER Working Paper \#2268

May 1987

\title{
Stabilization with Exchange Rate Management Under Uncertainty
}

\begin{abstract}
Stabilization programs in open economies typically consist of two stages. In the first stage the rate of currency develuation is reduced, but the fiscal adjustment does not eliminate the fiscal deficit which causes growth of debt and loss of reserves, making a future policy change necessary. Only later, at a second stage, is this followed by either an abandonment of exchange rate management or by a sufficiently large cut in the fiscal deficit. We study how different second-stage policy changes affect economic dynamics during the first stage. These changes include tax increases, budget cuts on traded and nontraded goods, and increases in the growth rate of money. Under certainty about the timing and nature of a switch, current account developments provide information about which policy instrument is expected to be used for stabilization. Uncertainty about the timing of a stabilization is shown to be important in explaining phenomena such as continuous reserve losses and the possibility that a policy change is accompanied by a surprise discrete devaluation rather than a run on reserves.
\end{abstract}

Allan Drazen Department of Economics Tel Aviv University

Ramat Aviv, Israel 69978 (03) 420-488
Elhanan Helpman Department of Economics Tel Aviv University Ramat Aviv, Israel 69978 (03) $420-712$ 


\section{Introduction}

Several countries have attempted to reduce inflation via exchange rate management. Sometimes it was the main instrument, as in the case of Argentina and Chile in the late seventies; sometimes it was part of a comprehensive policy package, as in the case of Argentina and Israel in 1985. However, in all these cases exchange rate management was attempted without an immediate balancing of the government's budget which would make the policy sustainable over the long run. Expectations of a future policy change were therefore engendered. One may therefore think about such policies as two-stage programs, where in the first stage the exchange rate is frozen or the rate of currency devaluation is substantially redued, while in the second stage the budget deficit is eliminated or exchange rate management is abandoned. In Drazen and Helpman (1987) we studied such programs for economic environments with complete certainty, including certainty about timing of the second-stage policy adjustment. Here we extend the analysis to an environment in which there is uncertainty about the timing of the second-stage change.

The introduction of uncertainty helps to explain certain observed phenomena which cannot be explained in its absence. These include discrete devaluations upon the abandoning of exchange rate management and runs on reserves which are not associated with the abandoning of exchange rate management. Our work is in the spirit of Krugman (1979) and elaborations which followed, such as Flood and Garber (1984).

Our basic model is described in section 2. In Section 3 we discuss the certainty case in order to set the stage for a discussion of the role of uncertainty. Finally, in Section 4 we distuss stabilization under timing uncertainty. 


\section{The Basic Model}

We consider a simple open economy model identical to that in Drazen and Helpman (1987). There are two consumption goods, traded and nontraded. Current macroeconomic policy, consisting of a fixed level of public spending on traded and on nontraded goods, fixed taxes in terms of traded goods, and a fixed exchange rate, is infeasible in the long run. The precise nature of this infeasibility will be spelled out later. There are no restrictions on international capital movements, which, combined with the exchange rate policy, means that the government has no direct control over the money supply. Stabilization is effected by a change in at least one policy variable that is under direct control of the government.

The utility of the representative individual is assumed to depend on consumpton of the two goods and real money balances, where the instantaneous utility function is assumed separable across consumption and real balances. This is represented by

$$
u\left(c(t), c_{N}(t)\right)+v(M(t) / Q(t)),
$$

where $t$ is a time index, and $c, c_{N}$, and $M$, are real consumption of traded goods, nontraded goods, and nominal domestic currency balances. $Q$, the domestic currency price index of the two goods, is defined by $Q(t)=Q\left(\epsilon(t), P_{N}(t)\right)$, where $\epsilon$ is the exchange rate (the domestic currency price of foreign exchange), the foreign currency price of traded goods is constant and equal to one, and where $\mathrm{P}_{\mathrm{N}}$ is the domestic currency price of nontraded goods. The functions $u(\cdot)$ and $v(\cdot)$ are increasing and concave, and the function $Q(\cdot)$ is increasing and positively linear homogeneous. 
The individual may hold domestic currency or bonds denominated in foreign currency, denoted $b$, with the latter paying the exogenously fixed world interest rate $r$. We assume that the individual's subjective discount rate equals $r$ and that he receives fixed income of $y$ in terms of traded goods plus $y_{N}$ in terms of nontraded goods. The assumption of constant output levels eliminates employment considerations while the equality of the subjective discount rate to the real interest rate in terms of traded goods eliminates secular trends in the trade account. This allows us to focus attention on the speculative aspects of stabilization.

We consider the case where the timing of a stabilization is not known ex-ante. We assume that the switch may occur at any time between 0 and some $\mathrm{T}_{\max }$, where the cumulative distribution of a switch occuring until $\mathrm{T}$ is $F(T)$. Clearly $F(0)=0$ and $F\left(T_{\max }\right)=1$. We consider the case where only one switch takes place.

The individual maximizes expected discounted utility over his horizon subject to his budget constraints, the expectation taken over $\mathrm{dF}(\mathrm{T})$. It will be useful to write the individual's present discounted utility if a switch occurs with certainty at $T$ as follows. Let $V^{s}(\cdot)$ be the present discounted value of maximized utility from $T$ onwards. It will be a function of the real value of an individual's assets at $T$, and perhaps of $T$ as well. The present discounted utility from 0 to infinity if a switch occurs at $T$ is then (using the instantaneous utility function from above):

$$
\begin{aligned}
\int_{0}^{T} e^{-r t}\left[u\left(c(t), c_{N}(t)\right)+v(M(t) / Q(t))\right] d t & \\
& +e^{-r T V^{s}[b(T)+m(T) ; T]}
\end{aligned}
$$


where $b(T)$ is the stock of private bond holding at the time of stabilization and $m(T)$ is the stock of real balances. Expected welfare is then the expected value of (1) taken over all possible realizations of $T$. The individual can switch between money and bonds at any instant of time. Using traded goods as the nimeraire, his budget constraint may be written as,

$$
\begin{aligned}
\int_{0}^{\infty} e^{-r t}\left[c(t)+\frac{P_{N}(t)}{\epsilon(t)} c_{N}(t)+\frac{z(t)}{\epsilon(t)}+r(t)-y\right. & \left.-\frac{P_{N}(t)}{\epsilon(t)} y_{N}\right] d t \\
& +\Sigma_{t_{i}} e^{-r t} \frac{\Delta M\left(t_{i}\right)}{\epsilon\left(t_{i}\right)} \leq b_{0},
\end{aligned}
$$

where $z(t)$ is the flow addition to nominal balances, $\tau(t)$ is the level of non-distortionary taxes in terms of traded goods, $\Delta M\left(t_{i}\right)$ is the stock increase in domestic currency holdings resulting from sale of foreign currency to the monetary authority, and $b_{0}$ is the initial stock of bonds. All variables in these equations represent values conditional on no policy switch taking place before $t$. Asset swaps take place at discrete points in time $t_{i}$. The evolution of the stock of private bond holdings $b(t)$ is given by

$$
\dot{b}=r b-c-\frac{P_{N}}{\epsilon} c_{N}-\tau+y+\frac{P_{N}}{\epsilon} y_{N}-\frac{z}{\epsilon} \quad \text { for } t+t_{i}
$$

(2')

$$
b\left(t_{i}\right)-b\left(t_{i}^{-}\right)=-\Delta M\left(t_{i}\right) / \epsilon\left(t_{i}\right)
$$

Nominal domestic balances at $t$ are related to $z$ and $\Delta M$ via

$$
M(t)=M_{0}+\int_{0}^{t} z(x) d x+\Sigma_{t_{i} \leq t} \Delta M\left(t_{i}\right) \quad \text { for all } t
$$


where $M_{0}$ is the initial stock of money holdings.

The individual chooses the functions $c(t), c_{N}(t), M(t), z(t)$, the timing of stock adjustments $t_{i}$ and their size $\Delta M\left(t_{i}\right)$, to maximize the expected value of the objective function given in (1) under constraints (2) and (3). (The reader may refer to the Appendix for the exact mathematical formulation.)

Using the clearing condition in the market for nontraded goods

$$
c_{N}(t)+g_{N}(t)=y_{N}
$$

where $g_{N}(t)$ is government purchase of nontraded goods, the first-order conditions of this problem imply (see the Appendix):

$$
\theta(t)=\int_{t}^{\mathrm{T}} \theta^{\mathrm{max}}(\mathrm{T}) \frac{\mathrm{dF}(\mathrm{T})}{1-\mathrm{F}(\mathrm{t})} \quad \text { for } \quad t<\mathrm{T}_{\max }
$$

$$
p\left[c(t), y_{N}-g_{N}(t)\right]=\frac{u_{2}^{\prime}\left[c(t), y_{N}-g_{N}(t)\right]}{u_{1}^{\prime}\left[c(t), y_{N}-g_{N}(t)\right]}=\frac{P_{N}(t)}{\epsilon(t)} \quad \text { for all } t
$$

$$
\begin{array}{rr}
\frac{1}{\epsilon(t)}=\frac{1}{\theta(t)} \int_{t}^{T \max }\left[e^{-r(T-t)} \frac{\theta^{s}(T)}{\epsilon^{s}(T)}+\int_{t}^{T} e^{-r(x-t)} \frac{v^{\prime}(x)}{Q(x)} d x\right] \frac{d F(T)}{1-F(t)} \\
\text { for } t<T_{\max }
\end{array}
$$

where a superscript $s$ indicates the value of a variable after stabilization. Thus, $\theta^{s}(\mathrm{~T})$ is the marginal utility of consumption of traded goods at time $T$ provided stabilization takes place at time $T$ and $\epsilon^{s}(T)$ is the exchange 
rate at time $T$ provided stabilization takes place at time $T$. The value of $T_{\max }$ is smaller than or equal to the point in time at which the government reaches the limit of its ability to finance the budget without further growth of net debt. We.will say more about this point in due course.

Equation (5) says that traded goods consumption is chosen at each point before a stabilization to equalize current marginal utility of consumption to conditional expected future post-stabilization marginal utility (that is, conditional on no stabilization before $t$ ). This condition allows for the fact that the marginal utility of consumption after a stabilization may depend on the timing of the stabilization. Equation (6) represents the standard equality of the marginal rate of substitution to relative prices. The marginal rate of substitution $p(\cdot)$ is equal to the inverse of the real exchange rate, where the real exchange rate is defined as the price of nontradeables in terms of tradeables. Equation ( 7 ) is an asset pricing equation of money balances, with the return on the asset being uncertain. The left-hand side is the real value in terms of traded goods of one unit of nominal balances at $t$. On the right-hand side, the term inside brackets is the sum of the present discounted value of the resale value of one unit of money at $T$ (in marginal utility terms) and the discounted value of the flow of utility from money holdings from $t$ until $T$. Taking the expectation over all possible switch time gives expected returns which, on division by $\theta(t)$, is in the same units as the left-hand side.

The government, which consists of a fiscal and monetary authority, faces the following consolidated budget constraint: 
(8)

$$
\begin{aligned}
\int_{0}^{\infty} e^{-r t}\left[g(t)+\frac{P_{N}(t)}{\epsilon(t)} g_{N}(t)-\tau(t)\right. & -z(t) / \epsilon(t)] d t \\
& -\Sigma_{t_{i}} e^{-r t} \Delta \Delta\left(t_{i}\right) / \epsilon(t)+b_{0}^{G}=0
\end{aligned}
$$

where $g(t)$ is purchases of traded goods, $g_{N}(t)$ is purchases of nontraded goods, and $b_{0}^{G}$ is initial net debt in terms of traded goods. Net government debt equals outstanding debt minus reserve holdings, where outstanding debt is denominated in terms of foreign currency. Implicit in (8) is the assumption that foreign exchange reserves, like all other foreign currency denominated assets, bear interest at the rate $r$.

The evolution of the government's net debt $b^{G}(t)$ is given by $\left(8^{\prime}\right)$

$$
\dot{b}^{G}=r b^{G}+g+p g_{N}-\tau-\dot{M} / \epsilon \text { for } t r t_{1}
$$

$$
b^{G}\left(t_{1}\right)-b^{G}\left(t_{i}^{-}\right)-\Delta M\left(t_{1}\right) / \epsilon\left(t_{1}\right)
$$

where use has been made of (3) to derive $\dot{M}-z$ for $t a t_{i}$, since the stock of money is not under the government's direct control when it controls the exchange rate.

The difference between government net debt $b^{G}$ and private holding of interest-bearing assets $b$ is net foreign indebtedness, which we denote by $\vec{b}-$ $b^{G}$ - b. Using $\left(2^{\prime}\right),\left(8^{\prime}\right)$, and the clearing condition in the market for nontraded goods (4), we obtain

$$
\dot{\bar{b}}=\mathrm{r} \overline{\mathrm{b}}+\mathrm{g}+\mathrm{c}-\mathrm{y} \quad \text { for all } \mathrm{t}
$$


where the right-hand side represents the deficit on current account.

It is clear that if (2) and (8) hold, meaning the private and government sectors are intertemporally balanced, then the present value of net external debt is nonpositive (i.e., $\lim _{t \rightarrow \infty} e^{-r t} \bar{b}(t) \leq 0$ ), and the economy is also intertemporally balanced.

\section{Stabilization under Certainty}

We consider a situation where the government fixes the exchange rate $\epsilon$ without eliminating the budget deficit, implying growing government debt. In addition, the spending levels $g$ and $g_{\mathrm{N}}$ and the tax level $\tau$ are maintained constant before stabilization. Stabilization takes place at a point in time $T$ at which the government changes its policy instruments to new constant levels so as to freeze its net debt at its then current level $b^{G}(T)$.

The case of certainty about the timing of a stabilization may be seen as a special case of this formulation, where the probability distribution has all its mass at a single $T$. This case, which is discussed in greater detail in Drazen and Helpman $(1986,1987)$, is meant to set the stage for the uncertainty results. In the certainty case equation (5) would imply constancy of $\theta$ over time. This implies that private consumption of tradeables and nontradeables is also constant before $T$, as well as being constant after $T$, although not necessarily at the same level. Then (6) implies constancy of the real exchange rate. Moreover, given the fixed exchange rate before $T$, (6) implies a constant price of nontraded goods $\mathrm{P}_{\mathrm{N}}$ and a constant price level $\mathrm{Q}$ before $T$. In the steady state that is reached after stabilization, the triple $\left(\epsilon, P_{N}, Q\right)$ is rising at the rate of money growth $\mu$. When the marginal utility 
of consumption $\theta$ is constant, (7) implies that the exchange rate $\epsilon$ is continuous even at $T$. Under these circumstances differentiation of the first-order conditions yields (see the Appendix)

$$
\frac{v^{\prime}(m / q)}{\theta q}=r+\mu \quad \text { for } t \geq T
$$

(with $\mu=0$ for $t<T$ under certainty), where $q-Q / \epsilon$ and real balances $m$ are defined as $M / \epsilon$. The variable $q$ is an alternative representation of (the inverse of) a real exchange rate, with the real exchange rate here defined as the price of traded goods in terms of a domestic basket of goods. In what follows we use the earlier definition of the real exchange rate as the price of traded goods in terms of nontraded, that is (by (6)) the inverse of $p(\cdot)$. $q$ is an increasing function of $p$ (or a declining function of the real exchange rate), since the price index function $Q\left(\epsilon, P_{N}\right)$ is positively linear homogeneous, so that $q=q[P(\cdot)]=Q\left(1, P_{N} / \epsilon\right)-Q[1, P(\cdot)]$.

Equation (10) implies constant nominal money balances before $\mathrm{T}$ (since the exchange rate is fixed). Hence,

(11) $z=\dot{M}=0$ and $\Delta M=0$ for $t, t_{i}<T$, and, from (8),

$$
\dot{b}^{G}=r b^{G}+g+p g_{N}-\tau-\mu m \text { for } t \geq T
$$

with $\mu=0$ for $t<\mathrm{T}$. Our primary interest in these equations is to derive 
the post-stabilization terminal surfaces, which are relavant also in the case of timing uncertainty. We will simply describe the characteristics of the dynamic paths prior to stabilization, referring readers to our earlier papers for more precise details.

When the stabilization date is known, some qualitative characteristics of the dynamic path before a stabilization takes place do not depend on the instruments that are used to stabilize. For every value of $b^{G}$ larger than $\underline{b}^{G}$ $=-\left(g+\mathrm{pg}_{\mathrm{N}}-\tau\right) / \mathrm{r}$ government net debt will grow without bound for unchanged policy parameters. At all $t<T$ money balances are constant, as is private consumption of traded and nontraded goods.

In the case of stabilizations effected by an increase in taxes, $T$, or a cut in government consumption of traded goods, $g$, with no reliance on money growth, real balances before $T$ will be identical to those held after $T$, so there will be no need for an asset swap. In this case the locus of $m-b$ combinations described by (10) and (12) is simply a horizontal line at the pre-stabilization level of $m$, as in Figure $I$.

The anticipation of a $g$-based stabilization brings about an increase in net external debt for $t<T$, but a constant level of private bond hoidings. Since more resources will become available for private consumption after the budget cut, the private sector's consumption of traded goods prior to $T$ is larger than income from traded goods and foreign asset holdings, generating a deficit on current account prior to stabilization. The resources released by the spending cut at $T$ will be just sufficient to pay for the extra interest on the additional foreign debt, by which the deficit on current account has been financed. Constant private bond holdings and rising net government debt 
imply that all increases in net government debt result from foreign borrowing, budget deficits being financed by external debt. The consumption of tradeables is $c=\mathrm{rb}_{0}+\mathrm{y}-\tau+\mathrm{Pg}_{\mathrm{N}}$, which is independent of $\mathrm{T}$ (see Drazen and Helpman (1987)).

A stabilization via an increase in taxes with no rellance on monetary injections has similar implications for growth in the government's net debt and constant money balances. However, unlike the case of a g-based stabilization, a tax-based stabilization brings about a balanced current account, which means that prior to $T$ consumption is equal to income from traded goods and foreign asset holdings. Constant private consumption and net wealth are maintained by rising bond holdings which compensates for the rising present value of tax obligations, with the reverse taking place within the government sector. This means that the increase in government net debt is held entirely by domestic residents, budget deficits being financed by internal debt. Moreover, there is a unique value of $c$ that will bring about this outcome, namely, $c=y-g-r \bar{b}_{0}$. As in the earlier case, this consumption level does not depend on the timing of stabilization. This observation will prove useful at a later stage (see Drazen and Helpman (1987)).

A third case is a stabilization via a reduction in government spending on nontradeables، with no reliance on money financing. It is straightforward to show that a reduction in $g_{N}$ (implying an increase in $c_{N}$ at $T$ ) reduces the relative price of nontraded goods $p$ and $q$, and that it increases private consumption of tradeables if and only if $: u_{12}(\cdot)>0$. This means that at the moment of stabilization there is a real exchange rate devaluation resulting 
from a downward jump in the price of nontradeables $P_{N}$; the nominal exchange rate remains constant. Prior to stabilization, consumption of tradeables has to be sufficiently low so that the implied current account surplus and foreign asset accumulation generate enough interest earnings to cover the costs of the increased consumption of traded goods.

Since the budget cut reduces aggregate government spending in terms of tradeables (which is helped by the real devaluation), the $\dot{b}^{G}=0$ line in Figure I moves to the right. The fall in $q$ implies a fall in the value of $m$ which satisfies (10) when the elasticity of $v^{\prime}(\cdot)$ is larger than one in absolute value. (See Drazen and Helpman (1986) for a discussion of both this and the interest-elastic case.) Since the elasticity of the demand for money with respect to the interest rate is equal to the inverse of the elasticity of $v^{\prime}(\cdot)$, this implies that $m$ declines as a result of a cut in $g_{N}$ if and only if the elasticity of money demand is smaller than one. Thus, the curve $m_{s}^{N}\left(b^{G}\right)$ in Figure II describes all steady state points that can by attained by means of a cut in $g_{N}$ with an interest inelastic demand function for money. The fall in $m$ at the time of stabilization will clearly come about via an asset swap in the certainty case (see Drazen and Helpman (1987)).

In the previously discussed cases stabilization at $T$ did not require abandoning the fixed exchange rate. When stabilization is effected via an increase in the rate of monetary growth $\mu$, it must be abandoned. An increase in the rate of monetary growth does not change private consumption levels and the real exchange rate, but it nevertheless affects both of the steady state loci. After $T$ the rate of depreciation $\dot{\epsilon} y \in$ must equal $\mu$, and (10) implies that an increase in $\mu$ shifts down the steady state value of $m$. A positive 
value of $\mu$ means that the line $\dot{b}^{G}=0$ will be upward sloping rather than vertical (see (12)), increases in $\mu$ shifting the line down. Therefore, as long as increases in $\mu$ increase seignorage the new steady state point will lie to the southeast of the original point, as does point $D$ relative to point $E$ in Figure III. The locus of steady state combinations can be represented by the curve $\mathrm{m}_{\mathrm{s}}^{\mu}\left(\mathrm{b}^{G}\right)$. We assume that the government chooses the lowest possible rate of money growth whenever there is more than one value that can finance the budget deficit. As in the previous case, under certainty the fall in $m$ at the time of stabilization is brought about via a run on foreign exchange reserves.

Since a money-based stabilization relies on the collection of an inflation tax, it will have identical consequences to a tax-based stabilization for consumption, the current account, and debt prior to $T$ as long as preferences are additively separable between consumption and real money balances. A difference emerges at $T$ because in anticipation of an inflation tax there is a run on reserves and a drop in money holdings, while no run takes place in anticipation of a lump-sum tax (see Drazen and Helpman (1987)).

To summarize the results under certainty, current account developments provide information about what type of stabilization is expected. There will be a deficit pn current account when a budget cut on traded goods is expected, a surplus when the expected change is a budget cut on non-traded goods, and a balanced current account when a tax-based or money-based stabilization is expected. Until the point of stabilization money balances are constant, implying no loss of reserves. At the point of stabilization there will be a 
discrete change in money demand, and hence a run on reserves, in two cases, those of a $g_{\mathrm{N}}$-based and a money-based stabilization. The first is due to the real exchange rate change which accompanies the stabilization, the second to the accompanying increase in the nominal interest rate. In all cases the path of the nominal exchange rate is continuous not only before a stabilization, but at the point of stabilization as well. In no case is a stabilization whose timing is certain accompanied by a discrete devaluation.

In actual practice, however, a policy of fixing the exchange rate without balancing the budget often puts continual pressure on foreign exchange reserves, causing partial runs which do not imply immediate abandonment of the given policy. Even in the absence of discrete runs, fixing the exchange rate in a way known to be unsustainable in the long run usually causes a continuous loss of reserves. When the policy is abandoned, a discrete nominal devaluation often takes place (see Helpman and Leiderman (forthcoming)). None of these observed phenomena can be explained by the certainty model, but, as will be shown below, can arise when there is uncertainty about the timing of a stabilization.

\section{The Importance of Timing Uncertainty}

We now return to the more general formulation to show how timing uncertainty can explain the above phenomena. Under uncertainty, the first-order conditions (5) through (7) have a number of implications. First, as $t$ approaches $T_{\max }$, they imply

$$
\theta \mathbf{s}\left(T_{\max }\right)=\theta\left(T_{\max }\right)
$$


and

$$
\epsilon^{S}\left(T_{\max }\right)=\epsilon\left(T_{\max }\right)
$$

Namely, at the moment in which stabilization is sure to take place if it did not take place before, there can be no jump in the marginal utility of consumption of tradeables or in the exchange rate. This stems from the fact that at $T_{\max }^{-}$there is no residual uncertainty, so that we obtain the same results as in the case of certainty.

Differentiation of the first-order conditions, taking into account the fact that the exchange rate is fixed prior to stabilization and assuming that $F(T)$ is differentiable for $T<T_{\max }$, yields

$$
\frac{\dot{\theta}}{\theta}=\frac{\mathrm{f}}{1-\mathrm{F}}\left(1-\frac{\theta}{\theta}^{\mathrm{s}}\right) \quad \text { for } \quad \mathrm{t}<\mathrm{T}_{\max }
$$

and

$$
\frac{v^{\prime}}{\theta q}=r+\frac{f}{1-F} \frac{\theta^{s}}{\theta}\left[1-\frac{\epsilon}{\epsilon}\right] \quad \text { for } t<T_{\max }
$$

where $f$ is the density function of $F$. The right hand side of (16) represents the nominal interest rate, which equals the interest on foreign currency denominated assets plus a term reflecting the expected capital gain or loss on nominal balance holdings as a result of a possible exchange rate jump. This last term is the product of the density of a stabilization at $t$ conditional on no stabilization having occurred until $t$ (the hazard rate), the change in the marginal utility of consumption, and the percentage change in the foreign currency value of nominal balances due to an exchange rate jump. 
Given the available financing instruments of the government's consolidated budget, there is a maximum level of debt consistent with a stabilization. Therefore, one expects that if no stabilization has occurred before debt hits some $b_{\max }^{G}$, then a regime switch must occur at that point in time. More generally, one may argue that the probability of a stabilization grows as $b^{G}(t)$ approaches $b_{\max }^{G}$, with a stabilization occurring with certainty sometime between time 0 and the time that $b^{G}(t)$ hits $b_{\max }^{G}$. We therefore assume that the conditional density of a stabilization can be expressed as a non-decreasing function of the level of net government debt, name1y

$$
\frac{f(t)}{1-F(t)}=\phi\left(b^{G}(t)\right) \quad \text { for } \quad t<T_{\max }
$$

The restriction that $F\left(T_{\max }\right)=1$ will imply that $\phi(\cdot)$ becomes infinite as debt approaches $b_{\max }^{G}$, unless the distribution has a mass point at $T_{\max }$. For $\boldsymbol{r}$-based and $g$-based stabilizations, equilibrium time paths have the same characteristics as in the certainty case, because under certainty the trajectories did not depend on $T$, the date of stabilization. (See Drazen and Helpman (1986).) When stabilization is effected by changes in $\mu$ or $g_{\mathrm{N}}$ however, uncertainty about timing does have an effect.

Consider, first a stabilization effected by an increase in the rate of monetary growth, so that (12) is satisfied with $\dot{b}^{G}=0$ at the level of government debt attained at the date of stabilization. To analyze this path recall first that since consumption of traded goods is independent of $T$ in the certainty case, it will also be constant over time in this case. The locus 
of steady state points (the terminal surface) is $\mathrm{m}_{s}^{\mu}\left(b^{G}\right)$, as in the certainty case, and it is described in Figure III. With constant consumption of traded goods the marginal utility of consumption of traded goods is constant before and after a switch, so that, taking account of (17), (16) becomes

(16 $) \quad \frac{v^{\prime}(m / q)}{\theta q}-r+\phi\left(b^{G}\right)\left[1-\frac{m_{s}^{\mu}\left(b^{G}\right)}{m}\right] \quad$ for $t<T_{\max }$,

where use has been made of the fact that $M^{S}(t)=M(t)$ for $t<T_{\max }$. Since in this case stabilization also implies the abandoning of the fixed exchange rate, there can be no jump in the quantity of money after stabilization. Condition (16') describes a curve in $b^{G}-m$ space on which the system has to be prior to stabilization. The direction of its movement is determined by $\left(8^{\prime}\right)$, which can be reproduced here as

(8') $\quad \dot{b}^{G}+\dot{m}=r b^{G}+g+p_{\text {N }}-\tau$ for $t<T_{\max }$.

Our assumption is that at time zero the right hand side of ( $\left.8^{\prime}\right)$ is positive. Therefore, it remains positive if net government debt is rising over time.

The downward-sloping arrow curve in Figure III describes the direction of the system's movement. (See Drazen and Helpman (1986) for a proof.) On this trajectory net government debt is rising and money holdings are declining. The decline in money holdings results in reserve losses. If a policy switch takes place before point $Z$ is reached, the system jumps downwards to the terminal surface, like from $C$ to $D$. This jump cannont involve a discrete change in 
money holdings, because the policy switch brings to an end exchange rate stabilization. Hence, the jump results from an unexpected discrete exchange rate devaluation. The figure is drawn on the assumption that $F(\cdot)$ has a mass point at $T_{\max } \cdot$ (See Drazen and Helpman (1986) for details.) Therefore, if no policy switch takes place before the system reaches point $Z$, then when it reaches this point at $t=\mathrm{T}_{\max }^{-}$, there is a run on reserves which brings it to Q. The exchange rate does not jump at this last moment. Point $Z$ is defined by the intersection of the curve that satisfies (16') and a 45-degree line that passes through $Q \quad Q$ is the point on the terminal surface that corresponds to $b_{\max }^{G}$ ).

Our analysis implies that expectations of a money-financed stabilization lead to the same consumption levels and the same evolution of debt as expectations of a tax-based stabilization, but that in the presence of uncertainty they generate different expectations of exchange rate movements and therefore also different trajectories of money holdings. In the latter case no exchange rate jump is expected while in the former case a devaluation is expected to follow a policy switch at $t<T_{\max }$. Consequently, in the former case there are no changes in the nominal interest rate and money holdings while in the latter the nominal interest rate rises and money holdings decline over time.

We now consider a stabilization via a cut in expenditures on nontraded goods. For the discussion that follows it is assumed for simplicity that $u\left(c, c_{N}\right)$ is additively separable. In this case $c$ is constant over time and the same as the consumption level for a tax-based and a money-based stabilization, so that the current account is balanced. This stems from the 
fact that in the certainty case this property of the utility function implies a consumption level which is independent of the timing of stabilization. (See Drazen and Helpman (1986)).

When stabilization includes the abandoning of exchange rate management, the dynamic path is once again described by $\left(16^{\prime}\right)$ with the terminal surface for changes in $g_{N}$, namely $m_{s}^{N}\left(b^{G}\right)$, replacing $m_{s}^{\mu}\left(b^{G}\right)$ on the right-hand side. The system must be on this curve and its direction of movement is given by $\left(8^{\prime}\right)$. The path therefore depends on the characteristics of the terminal surface $m_{s}^{N}\left(b^{G}\right)$. In the previously discussed case where the interest elasticity of money demand is smaller than one and the terminal surface is falling, the dynamic path will be monotonically falling until the policy switch takes place, as depicted by the downward-sloping arrow path in Figure II. At $T_{\max }$ the system reaches point $\mathrm{z}$ if no policy switch took place before that, and then jumps to $Q$ via a run on reserves. ${ }^{3}$ If a policy switch takes place before point $Z$ is reached, the system jumps down to the terminal surface, as from point $C$ to point $D$. This jump results from an unexpected devaluation. The real exchange rate also depreciates.

If the government were to maintain the fixed exchange rate also after stabilization, then an unexpected policy switch would not result an exchange rate jump, but rather a run on reserves that would bring the system instantaneously to the terminal surface. In this case (16) implies that prior to stabilization the system moves on the horizontal line in Figure II, as in the certainty case, and if an unexpected policy switch takes place when it reaches point $A$ it jumps instantaneously to point B. Point $B$ is the 
intersection point between the terminal surface and a 45 -degree line that passes through A.

Hence, if the fixed exchange rate is not maintained after stabilization, the dynamic trajectory prior to stabilization is characterized by a rising nominal interest rate and a continuous reserve loss as a result of the decline in money holdings, followed by a surprise devaluation if the policy switch occurs before $T_{\max }$. If, on the other hand, the fixed exchange rate is maintained after the policy switch, there is no reserve loss on account of changes in the demand for money, but there is a run on reserves immediately following the policy switch.

To summarize, the above analysis demonstrates a number of effects of timing uncertainty for the non-traded-goods and money-based stabilizations. Before a stabilization there will be a gradual decline in money holdings brought about by a continuous loss of reserves. This arises from the nominal interest rate rising over time, reflecting a rising risk premium (which in turn reflects our assumption about the conditional probability of a switch being an increasing function of government debt). Moreover, a discrete jump in the nominal exchange rate will accompany a stabilization whenever exchange rate management is abandoned (except when there is no residual uncertainty about its timing). These characteristics are consistent with actually observed episodes, such as those discussed in Helpman and Leiderman (forthcoming)). Timing uncertainty may generate even richer time paths, a' few examples of which we now quickly discuss. In the case of a stabilization expected to be effected by a budget cut on non-traded goods, the slope of the terminal surface $m_{s}^{N}\left(b^{G}\right)$ will be positive when the interest elasticity of money demand 
is larger than one, and will change sign if money demand is neither everywhere elastic nor everywhere inelastic. In the first case the time path for real balances may be non-monotonic, while in the second case it must be non-monotonic, as inspection of $\left(16^{\prime}\right)$ indicates when $m_{s}^{N}\left(b^{G}\right)$ replaces $\mathrm{m}_{\mathrm{s}}^{\mu}\left(\mathrm{b}^{\mathrm{G}}\right)$. Non-monotonicity means we will have alternating periods of reserve gains and losses even with no money financing of the budget.

The above discussion on non-traded goods relied on the assumption that $u(\cdot)$ is additively separable; that is, $u_{12}=0$. Non-separability makes things more complicated. For $u_{12}$ positive but small one can show that the qualitative features of the dynamics described above will not change, except that the currrent account will be at least initially in surplus rather than being balanced. (A fuller discussion of this and the above extensions may be found in Drazen and Helpman (1986).)

Finally, the observed phenomenon of partial runs on reserves not necessarily associated with a breakdown of fixed exchange rates arises in our model when the density function associated with $F(\cdot)$ is not continuous (see also Drazen and Helpman (1986) for a discussion of mass points). For example, suppose that $F(\cdot)$ is continuous, but the density function $f(\cdot)$ has one point of discontinuity at which it jumps up. The economic interpretation of this is that if a particular point in time is reached and a policy change has not taken place so far, then the chances of a policy change in the near future increase discretely. This point in time may be associated with political or other relevant events. Clearly, the upward jump in $f(\cdot)$ induces an upward jump in the hazard-rate function $\phi(\cdot)$. Now suppose that stabilization is expected to be effected by money financing and hence the abandonment of the fixed 
exchange rate. Then it is clear from (16') that in this case the downward sloping arrow path in Figure III is discontinuous at the debt level at which $\phi(\cdot)$ is discontinuous. In particular, it consists of two parts, with the part further to the right being lower. The discontinuity reflects a downward jump in the demand for money which results from an upward jump of the interest rate. In turn, the upward jump in the interest rate is caused by an upward jump of the risk premium reflecting the jump in the conditional density $\phi(\cdot)$. Since these jumps are fully expected once this point in time is reached, the discrete adjustment of money balances will be effected by a run on reserves which will shift the system from the higher to the lower branch of the adjustment path. If no regime switch takes place at this point in time, the economy moves on the lower branch. Hence, the model explains runs on reserves that are not associated with a collapse of the exchange rate policy. 


\section{APPEADIX}

In this appendix, we derive the first-order conditions when the date $T$ of a switch is unknown. These will also apply to the certainty case when the probability distribution has all its mass at a single $T$. When the cumulative distribution of a switch occurring until $T$ is $F(T)$, maximization of the expected value of (1) in the text subject to constraints (2') and (2) may be written (where $b(T)$ has been calculated by integrating (2'))

(A.1)

$$
\begin{aligned}
& \left\{c(t), c_{N}(t), M(t), z(t), \Delta M\left(t_{i}\right)\right) \int_{0}^{T}\left[\int_{0}^{T} e^{-r t}\left[u\left(c(t), c_{N}(t)\right)+v\left(\frac{M(t)}{Q(t)}\right)\right] d t\right. \\
& +e^{-r T} v^{S}\left(e^{r T_{b}} b_{0}-\int_{0}^{T} e^{r(T-t)}\left[c(t)+\frac{P_{N}(t)}{\epsilon(t)} c_{N}(t)+\frac{z(t)}{\epsilon(t)}+r(t)-y\right.\right. \\
& \left.\left.-\frac{P_{N}(t)}{\epsilon(t)} y_{N}\right] d t-\Sigma_{t_{i} \leq T} e^{r\left(T-t_{i}\right)} \frac{\Delta M\left(t_{i}\right)}{\epsilon\left(t_{i}\right)}+\frac{M_{0}+\int_{0}^{T} z(x) d x+\sum_{t_{i}} \leq T \Delta\left(t_{i}\right)}{\epsilon(T)} ; T\right) \\
& \left.+\int_{0}^{T} \gamma(t)\left[M_{0}+\int_{0}^{t} z(x) d x+\sum_{t_{i} \leq t} \Delta M\left(t_{i}\right)-M(t)\right]\right] d F(T)
\end{aligned}
$$

where $\gamma(t)$ is the multiplier on constraint (2) in the text. Maximization of (A.1) with respect to each of the $c(t), c_{N}(t), M(t)$, and $z(t)$ yields (where $\theta(t)$ is the marginal utility of traded goods at time $t, u_{2}(t)$ is the marginal utility of nontraded goods, 'and where a superscript $s$ indicates the variable after stabilization) 
(A. 2)

$\int_{t}^{T} e^{-r t} \theta(t) d F(T)=\int_{t}^{T} e^{-r t} e_{\theta}(T) d F(T)$

(A.3)

$$
\int_{t}^{T} e^{-r t} u_{2}(t) d F(T)=\int_{t}^{T} e^{-r t} \theta s(T) \frac{P_{N}(t)}{\epsilon(t)} d F(T)
$$

(A.4)

$$
\int_{t}^{T} e^{-r t} v^{\prime}(t) \frac{1}{Q(t)} d F(T)=\int_{t}^{T} \gamma(t) d F(T)
$$

(A.5)

$$
\int_{t}^{T}\left[e^{-r T \theta^{s}}(T)\left(-\frac{e^{r(T-t)}}{\epsilon(t)}+\frac{1}{\epsilon s(T)}\right)+\int_{t}^{T} \gamma(x) d x\right] d F(T)=0 .
$$

Maximization with respect to $\Delta M\left(t_{i}\right)$ yields a condition identical to (A.5) for $t=t_{i} \cdot(A .2)$ simplifies to

$$
\theta(t)=\int_{t}^{\mathrm{T}} \theta_{\theta} s(\mathrm{~T}) \frac{\mathrm{dF}(\mathrm{T})}{1-\mathrm{F}(\mathrm{t})}
$$

(A.3) then yields equation (6) in the text. Since (A.4) implies $\gamma(t)=e^{-r t} v^{\prime}(t) \frac{1}{Q(t)},(A .5)$ becomes

(A.7) $\quad \frac{1}{\epsilon(t)}=\frac{1}{\theta(t)} \int_{t}^{T \max }\left[e^{-r(T-t)} \frac{\theta^{S}(T)}{\epsilon^{s}(T)}+\int_{t}^{T} e^{-r(x-t)} \frac{v^{\prime}(x)}{Q(x)} d x\right] \frac{d F(T)}{1-F(t)}$.

As $t$ approaches $T_{\max }$, (A.2) implies that $\theta\left(\mathrm{T}_{\max }\right)-\theta\left(\mathrm{T}_{\max }\right)$, while (A.6) implies that $\epsilon\left(T_{\max }\right)=\epsilon^{S}\left(T_{\max }\right)$. Differentation of (A.6) when $F(T)$ is differentiable yields equation (15) in the text while differentiation of (A.7) when $\epsilon$ is constant, taking account of (15), yields equation (16). . 


\section{References}

Drazen, Allan, and Elhanan Helpman, "Stabilization with Exchange Rate Management," Working Paper No. 41-86, Foerder Institute for Economic Research, Tel Aviv University, November 1986.

Drazen, Allan, and Elhanan Helpman, "Stabilization with Exchange Rate Management," Quarterly Journal of Economics (forthcoming).

Flood, Robert D., and Peter M. Garber, "Collapsing Exchange Rate Regimes: Some Linear Examples," Journal of International Economics XVII (1984), 1-13.

Helpman, Elhanan, and Leonardo Leiderman, "Slowdown of Devaluations, Monetary Accomodation, and Inflation: A Comparison of Argentina, Chile and Israel," Economics Quarterly, forthcoming (Hebrew).

Krugman, Paul R., "A Model of Balance-of-Payments Crises," Journal of Money. Credit and Banking XI (1979), 311-25. 


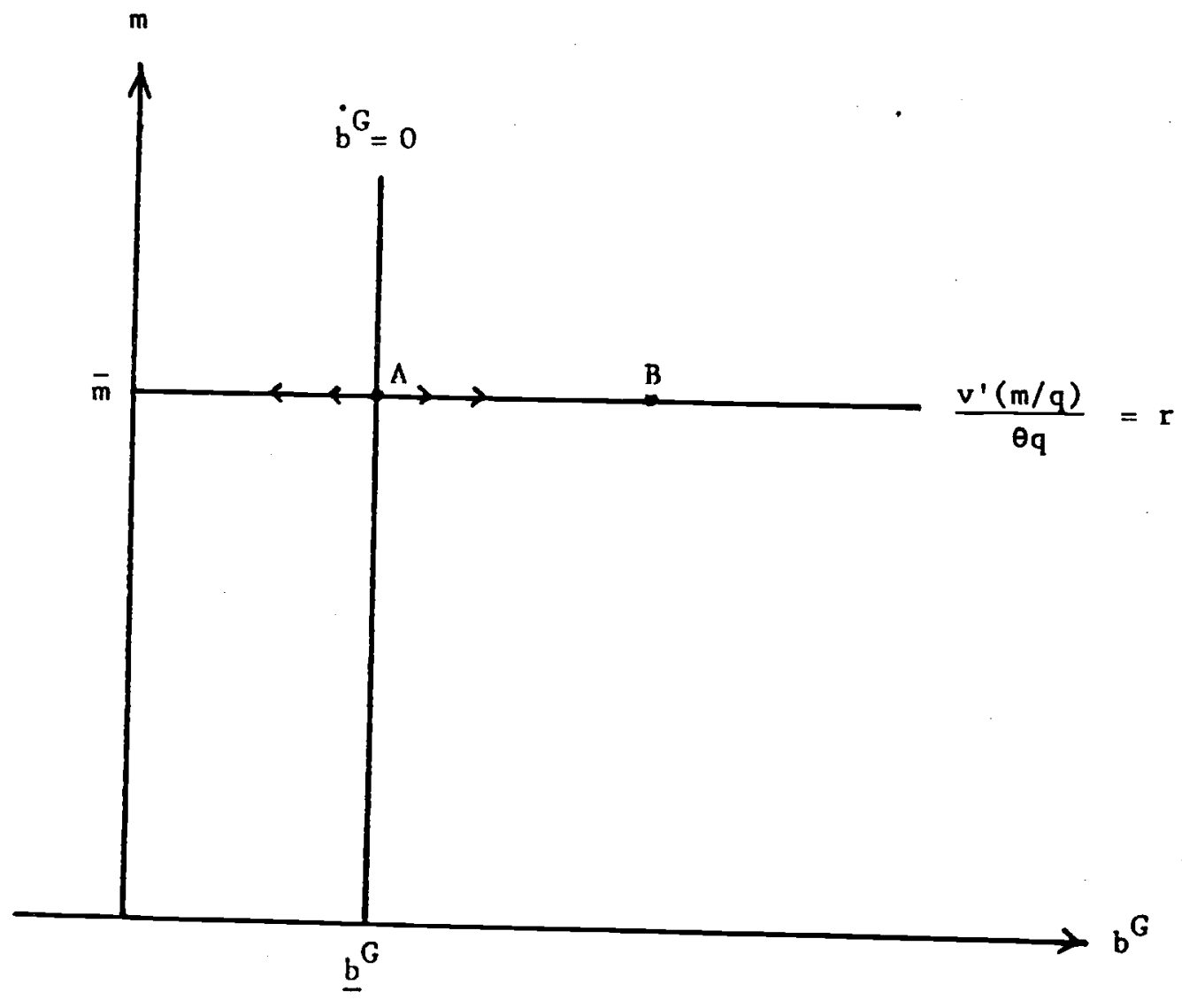

Figure I 


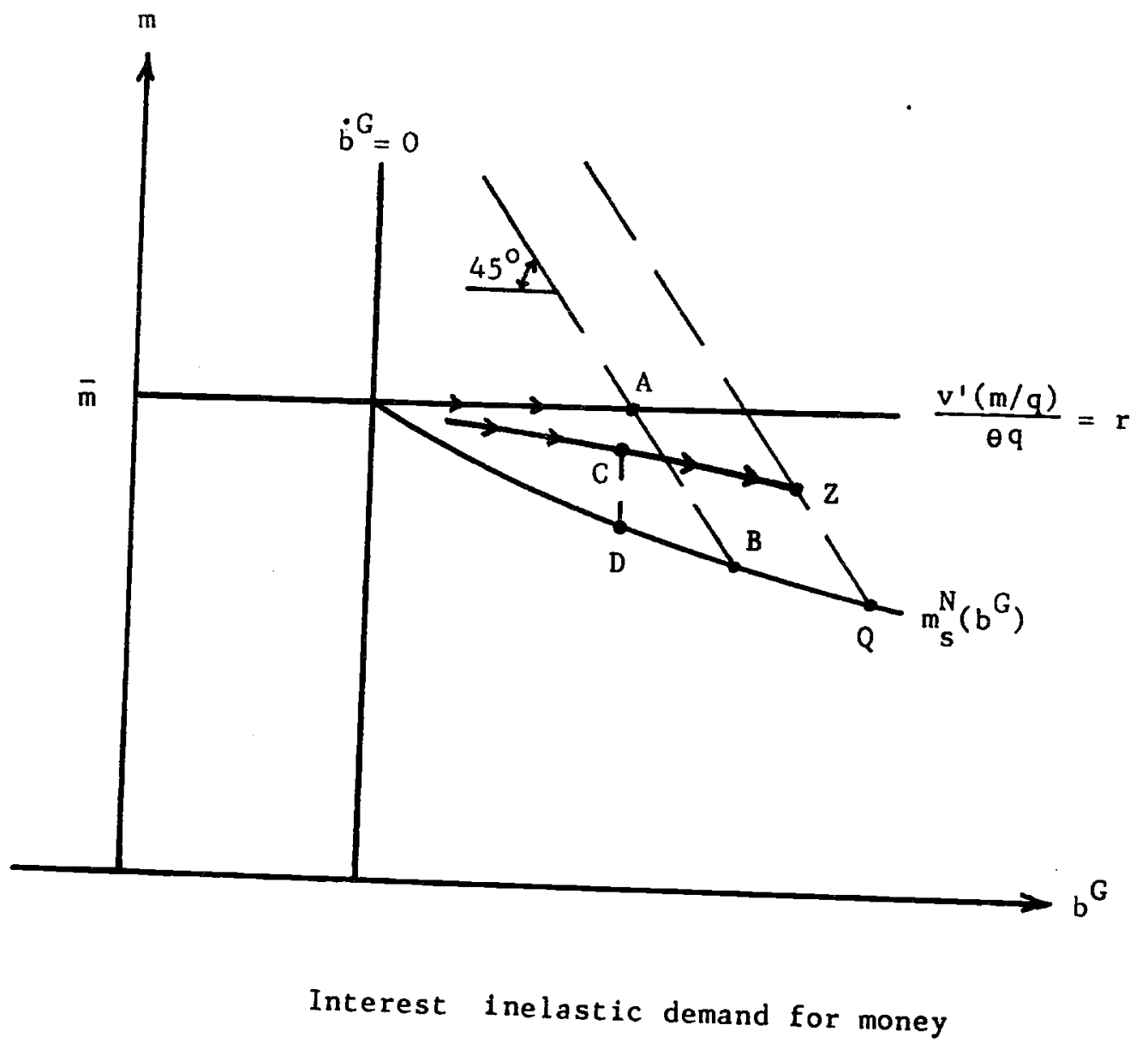

Figure II 


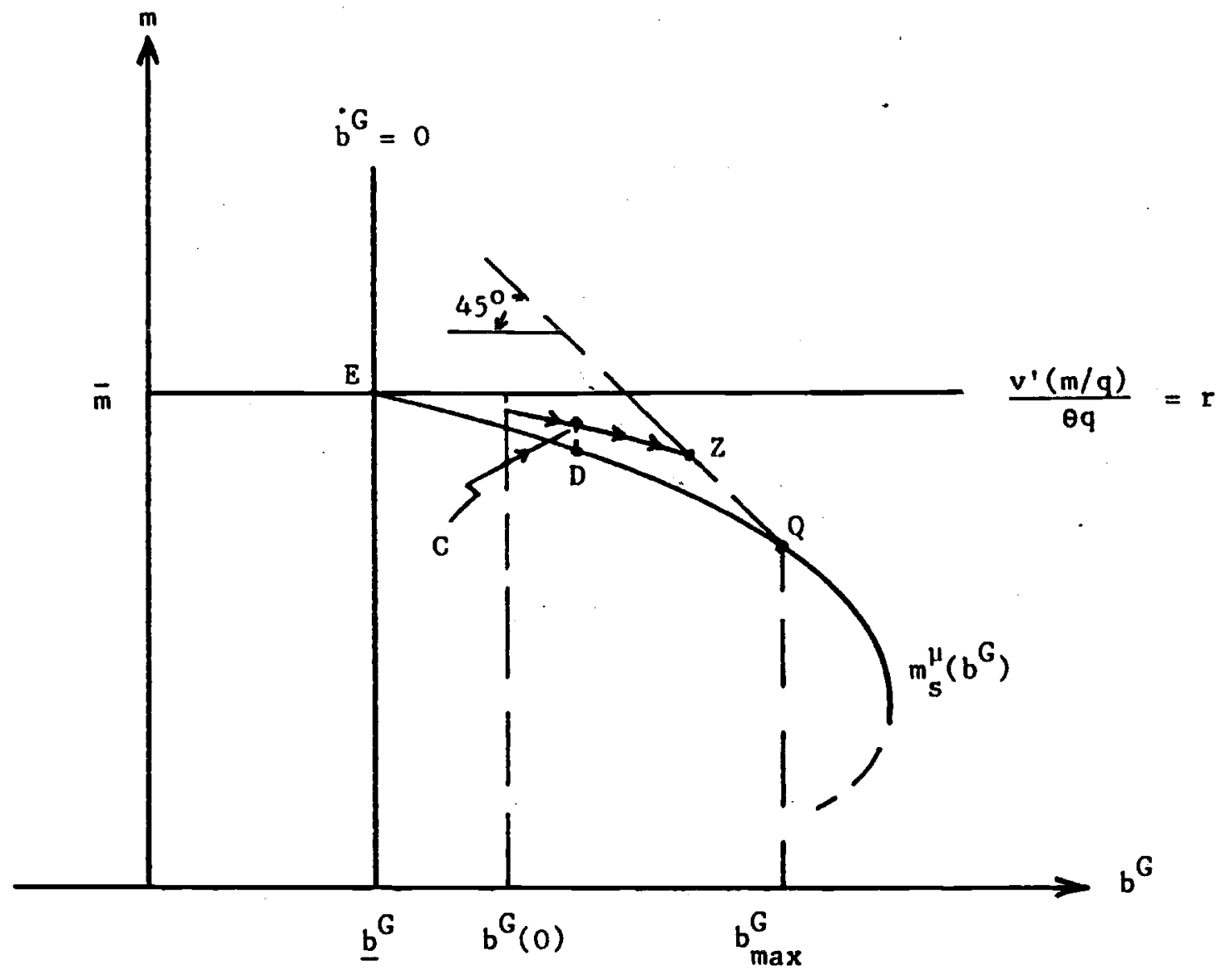

Figure III 